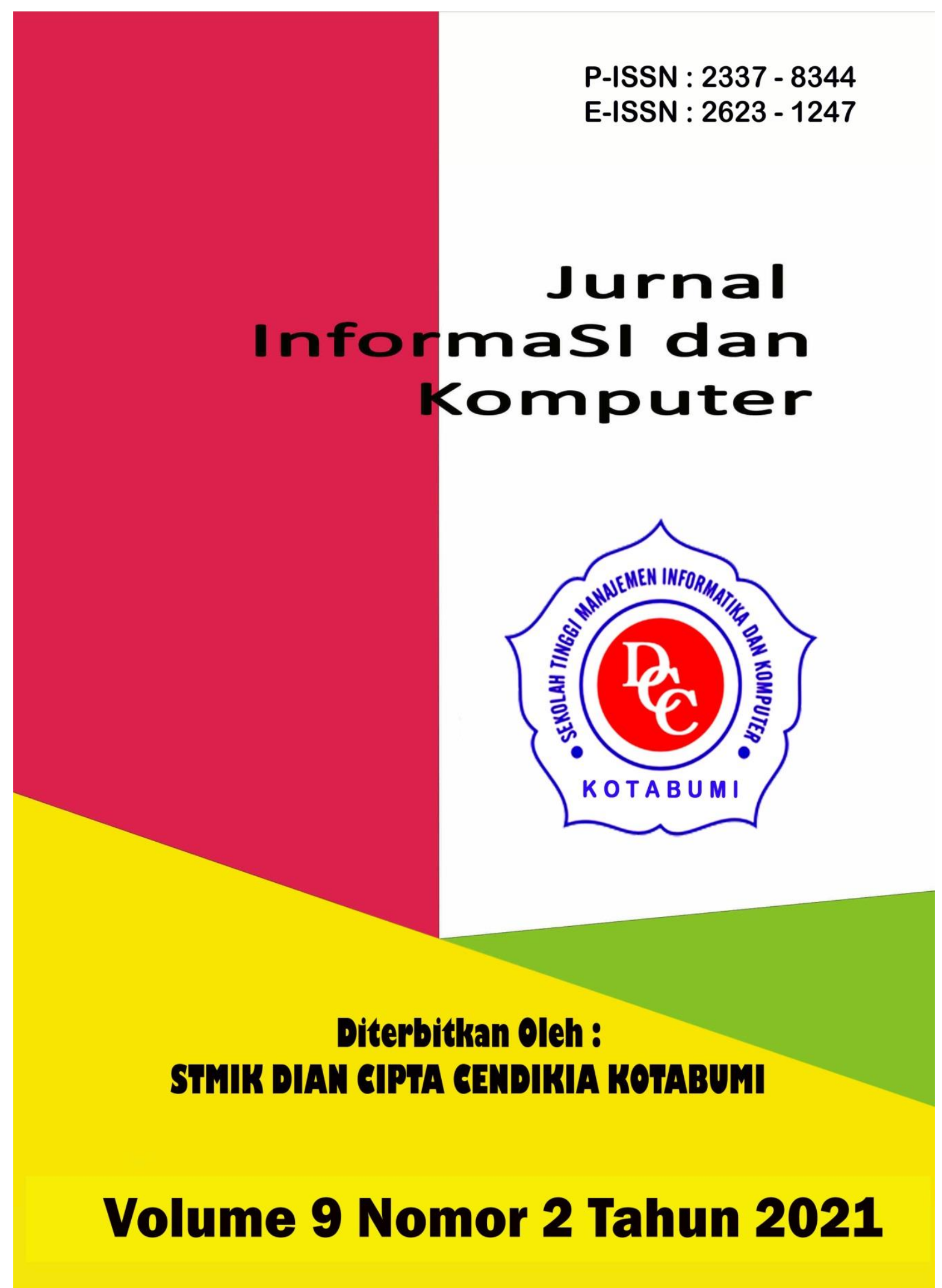




\section{Penerbit}

\section{Lembaga Penelitian STMIK Dian Cipta Cendikia Kotabumi}

Hak atas naskahh/tulisan tetap berada pada penulis, isi diluar tangung jawab penerbit dan Dewan Penyunting 


\section{PENGANTAR REDAKSI}

Puji syukur dipanjatkan kehadirat Tuhan Yang Maha Esa, atas karunia dan limpahan rahmatNYA jualah Jurnal Informasi dan komputer (JIK) STMIK Dian Cipta Cendikia Kotabumi ini dapat terwujud.Jurnal Informasi dan Komputer (JIK) yang terbit dua (2) kali dalam setahun ini merupakan suatu wadah untuk penyebar luasan hasil-hasil penelitian, studi pustaka, karya ilmiah yang berkaitan dengan Informasi dan Komputer khususnya bagi dosen-dosen STMIK Dian Cipta Cendikia Kotabumi serta umumnya para cendikiawan, praktisi, peneliti ilmu Informatika dan Komputer.

Harapan, dengan diterbitkannya Jurnal Informasi dan Komputer (JIK) ini sebagai salah satu bentuk sumbangan pemikiran dalam pengembangan ilmu informatika dan komputer yang berkaitan dengan kajian-kajian di bidang tekhnologi Informatik, Komunikasi Data dan Jaringan Komputer, perancangan dan Rekayasa Perangkat Lunak, serta ilmu-ilmu yang terkait dengan bidang Informasi dan Komputer lainnya.

Berkenaan dengan harapan tersebut, kepada para peneliti, dosen dan praktisi yang memiliki hasil-hasil penelitian, kajian pustaka, karya ilmiah dalam bidang tersebut diatas, dengan bangga redaksi Jurnal Informasi dan Komputer (JIK) menerima naskah ringkasan untuk dimuat pada jurnal Informasi dan Komputer (JIK) STMIK Dian Cipta Cendikia Kotabumi dengan berpedoman pada penulisan naskah jurnal sebagaimana dilampirkan pada halaman belakang (Bagian kulit dalam) buku jurnal ini.

Mutu dari suatu jurnal ilmiah tidak hanya ditentukan oleh para pengelolanya saja, tetapi para penulis dan pembaca jualah yang mempunyai peranan besar dalam meningkatkan mutu jurnal Informatika dan Komputer ini. Merujuk pada realita ini kamu sangat mengharapkan peran aktif dari peneliti untuk bersama-sama menjaga dan memelihara keberlangsungan dari jurnal Informasi dan Komputer STMIK Dian Cipta Cendikia Kotabumi ini. Yang juga tidak kalah pentingnya dari partisipasi tersebut diatas, adalah saran dan kritik yang membangun dari pembaca yang budiman agar kiranya dapat disampaikan langsung kepada redaksi JIK. Saran dan kritik yang membangun akan dijadikan masukan dan pertimbangan yang sangat berarti guna peningkatan mutu dan kualitas Jurnal Informasi dan Komputer STMIK Dian Cipta Cendikia Kotabumi.

Tak lupa diucapkan terima kasih yang tak terhingga atas perhatian dan kerjasama dari semua pihak yang tak dapat disebutkan satu persatu hingga dapat diterbitkan nya Jurnal Informasi dan Komputer (JIK) STMIK Dian Cipta Cendikia Kotabumi. Semoga apa yang telah diperbuat untuk kebaikan akan menjadi amal ibadah, amin.

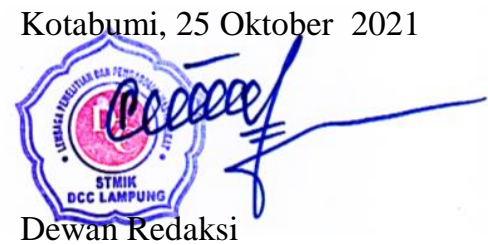




\section{JURNAL INFORMASI DAN KOMPUTER}

Volume 9 Nomor 2 Oktober 2021

Jurnal Informasi dan Komputer merupakan Sarana informasi ilmu pengetahuan, Tekhnologi dan Komunikasi yang berupa hasil penelitian, tulisan ilmiah, Ataupun studi pustaka. Jurnal ini terbit dua kali setahun pada bulan April dan Oktober. Berisi hasil penelitian ilmiah di bidang informatika yang bertujuan untuk menghubungkan adanya kesenjangan antar kemajuan teknologi dan hasil penelitian. Jurnal ini di terbitkan pertama kali pada tahun 2013.

Penanggung Jawab:

Ketua STMIK Dian Cipta Cendikia Kotabumi

\section{Pembina:}

Ketua STMIK Dian Cipta Cendikia Kotabumi Ketua Lembaga Penelitian STMIK Dian Cipta Cendikia Kotabumi

\section{Pimpinan Redaksi}

Dwi Marisa Efendi,.S.Kom.,M.Ti

\section{Redaksi pelaksana}

Rustam,.S.Kom,.M.Ti (STMIK Dian Cipta Cendikia Kotabumi)

Nurmayanti M.Kom (STMIK Dian Cipta Cendikia Kotabumi)

Sukatmi,.S.Kom., M.Kom (AMIK DCC Bandar Lampung)

Sampurna Dadi Riskiono,M.Kom (Universitas Teknokrat Indonesia)

Ifo Wahyu Pratama,S.Kom.,M.Ti(AMIK MASTER Lampung)

\section{Mitra Bestari}

Dr. RZ. ABDUL AZIZ, ST., MT (Institut Informatika dan Bisnis Darmajaya)

Dr. Dadang Sudrajat, S.Si, M.Kom (STMIK IKMI Cirebon)

Dr. Septafiansyah Dwi Putra, S.T., M.T (Politeknik Negeri Lampung)

Dr. Evi Grativiani, S.E., M.S.I (Universitas Sebelas Maret)

Rohmat Indra Borman ( Universitas Teknokrat Indonesia )

Ferry Wongso, S.KOm., M.Kom ( STMIK Darma Pala Riau)

Ferly Ardhy, S.Kom., M.Ti ( Universitas Aisyah Pringsewu )

Firmansyah, S.E., M.Si (STMIK Darma Pala Riau)
Amarudin (Universitas Teknokrat Indonesia)

Didi Susianto, S.T., M.Kom (AMIK Dian Cipta Cendika Bandar Lampung)

Alhibarsyah, St., M.Kom (STMIK Tunas

Bangsa Bandar Lampung)

Kemal Farouq Mauladi, S.Kom .M.Kom (Universitas Islam Lamongan)

Rima Mawarni, M.Kom ( STMIK Dian Cipta Cendikia Kotabumi)

Wira Jaya Hartono, S.Pd., M.Pd ( STMIK Darma Pala Riau)

Penerbit : STMIK Dian Cipta Cendikia Kotabumi Bekerja Sama Dengan LPPM STMIK Dian Cipta Cendikia Kotabumi.

\section{Alamat Redaksi/Penerbit:}

Jl. Negara No. 3 Candimas Kotabumi Lampung Utara

No Telpon/Fax 072423003

Email : 1ppm-stmik@dcc.ac.id 


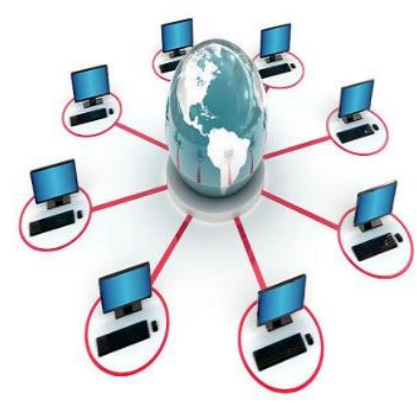

\section{JURNAL INFORMASI DAN KOMPUTER VOL. 9 NO. 2 THN. 2021}

\section{DAFTAR ISI}

Halaman

Sistem Informasi Akuntansi Persedian Barang Berbasis Web Pada Lembaga

Permasyarakatan Kelas II A Banceuy Bandung : "Kelompok Tani Desa Banjar Kertarahayu” Teuku Rian Hardiyansyah, Fatia Salsa Azzahra (Politeknik Piksi Ganesha Bandung ${ }^{1,2}$ ).

Penerapan Finite State Automata Pada Vending Machine Penjual Obat Non Resep

Dokter Dan Keperluan Medis

Eko Supriyanto $^{1}$, Angga Ardiansyah ${ }^{2}$, Frieyadie $^{3}$, Sri Rahayu ${ }^{4}$, Windu Gata ${ }^{5}$

(Universitas Nusa Mandiri ${ }^{12}$ )

Sistem Pendukung Keputusan Untuk Menentukan Kelayakan Pengajuan Sertifikasi Guru Dengan Metode Simple Additive Weighting (Studi Kasus : Ma Al Muhajirin Janti Jogoroto Jombang)

Budiman, umam baharudin, winarti

(Universitas Darul 'Ulum Jombang)

Perancangan Infrastruktur Domain Name Server Lokal Menggunakan Ubuntu Server 16.04

Pada PT. Xyz

Zaenal Mutaqin Subekti, Hendra Setiawan, Satria, Widia Murni Wijaya,

Aliy Hafiz, Warsudi

(STMIK Bani Saleh, Universitas Negeri Yogyakarta, AMIK Dian Cipta Cendikia,

STMIK MIC CIkarang)

Perancangan Sistem Informasi Idea Proposal (Ip) Berbasis Web Pada Pt. Paxel Algorita Unggul

Julian Murhan Sahputra, Indah Purnamasari

(Universitas Nusa Mandiri ${ }^{12}$ )

Sistem Pendukung Keputusan Untuk Menentukan Ekstrakurikuler Atletik

Berdasarkan Bakat Siswa Menggunakan Metode Profile Matching

Agnes Basuki, Petrus Sokibi, Tiara Eka Putri

(Universitas Catur Insan Cendekia)

Penerapan Algoritma K-Means Untuk Pengelompokan Usia Calon Penerima Vaksin

Di Kab. Ngawi

Irna Yuniarfi, Saifulloh

(Universitas PGRI Madiun ${ }^{12}$ )

System Penilaian Seleksi Calon Karyawan Baru Menggunakan Metode Simple Additive Weighting (SAW) Di PT.TNA

Anik Sri Wahyuningsih, Yudhi Firmansyah

(Universitas Panca Sakti Bekasi ) 
Perancangan Sistem Informasi Pembayaran SPP Menggunakan Framework Laravel Ichwan Habib Moudi

(Universitas Panca Sakti Bekasi)

Implementasi Algoritma K-Means Dan Algoritma Apriori Optimasi Kinerja Ecu

(Study Kasus Mobil Avanza Dan Xenia)

Sigit Mintoro' Asep Afandi

(STMIK Dian Cipta Cendikia Kotabumi)

Sistem Pakar Penyakit Buah Kakao Untuk Peningkatan Hasil Panen Kakao Menggunakan

Metode Case Base Reasoning (CBR) Berbasis Web Mobile

Aliy hafiz, Verawati

(AMIK Dian Cipta Cendikia,Bandar Lampung)

Penerapan Metode Rapid Application Develomment (RAD) Dalam Pengembangan

Sistem Pemesanan Menu Berbasis Android

Aris Baihaqi, Tumini

(Fakultas Sains dan Teknologi ${ }^{1,2}$ )

Rancang Bangun Sistem Informasi Geografis Pariwisata Di Lampung Timur

Sukatmi, Rexa Alfa Rizi

(AMIK DCC Bandar Lampung ${ }^{12}$ )

Implementasi Psak No. 45 Pada Proses Penyusunan Laporan Keuangan Menggunakan

M.S. Excel Dan Aplikasi Accurate Accouting Pada STMIK Bani Saleh

Marhakim, Willy Adam

(STMIK Bani Saleh ${ }^{12}$ )

Sistem Prediksi Harga KOPI LAMBAR ( Lampung Barat) Dengan Metode

Backpropagation, dan Double Exponential ( Studi Kasus BUMDES )

Supriyanto, Dwi marisa Efendi,Rhomadhon

(STMIK Dian Cipta cendikia Kotabumi ${ }^{1-}$ )

Sistem Informasi Pemasaran Produk Umkm Berbasis Web Pada Kecamatan Bumi

Nabung Lampung Tengah

Yuli Syafitri, Agus Prasetyo, Reni Astika

(AMIK Dian Cipta Cendikia Bandar Lampung)

Rancang Bangun Aplikasi Pembelajaran Aksara Lampung Berbasis Android

Ferly Ardhy, Hendra Syahrobi

(Universitas Aisyah Pringewu ${ }^{1,}$ STMIK Dian Cipta Cendikia ${ }^{2}$ )

Sistem Pakar Diagnosa Penyakit Kulit Pada Balita Menggunakan Metode Naïve

Bayes Dan Forward Chaining Studi Kasus Puskesmas Cempaka Sungkai Selatan

Sidik Rahmatullah, Rima Mawarni

(STMIK Dian Cipta Cendikia Kotabumi ${ }^{12}$ )

Rekayasa Perangkat Lunak Perhitungan Harga Pokok Produksi Metode

Full Costing Pada Umkm Mitra Cake Di Bandar Lampung

Pitrawati, Arif Sanjaya

(AMIK Dian Cipta Cendikia, Bandar Lampung) 
Rancang Bangun Sistem Ujian Online Menggunakan Algoritma Cosine Similarity

Berbasis Web

Haryono, Zaenal Mutaqin Subekti, Widiyawati, Hidayatullah

(STMIK Bani Saleh ${ }^{1234}$ )

Model Aplikasi Helpdesk Ticketing System Berbasis Web Menggunakan Metode Rad

Indra Permana

Pattern Recognition Tulisan Tangan Huruf Hijaiyah Menggunakan Metode

Convolutional Neural Network (CNN)

Mufassiril Abror, Nopiyanto

(Universitas Panca Sakti Bekasi ${ }^{12}$ )

Aplikasi Sistem Informasi Keuangan Berbasis Android Di Perumahan Taman

Karang Bahagia

Melda Ayulestari

(Universitas Panca Sakti Bekasi)

Audit Pelayanan Sistem Rujukan Online Puskesmas Menggunakan Framework COBIT 5.0

Nurmayanti, Merri Parida, Ngajiyanto, Ina Anzalna

(STMIK Dian Cipta Cendikia Kotabumi ${ }^{1234}$ )

Perancangan Sistem Informasi Pengolahan Data Nilai Siswa Berbasis Web

Erin Ermawati, Anik Sri Wahyuningsih

(Fakultas Sain dan Teknologi, Universitas Panca Sakti Bekasi ${ }^{12}$ )

Pengembangan Sistem Pelaporan Data Hasil Inspeksi Barang Berbasis Web

Siska Putriani

(Universitas Pancasakti Bekasi)

Penerapan Extreme Programming Dalam Perancangan Aplikasi Web Food Market

Tumini, Hilman Septiana

(Fakultas Sains dan Teknologi Universitas Panca Sakti Bekasi ${ }^{1,2}$ )

Sistem Pencarian Barang Berbasis Website Menggunakan Php Dan Mysql

Studi Kasus PT. Surya Technology Industri Sulaeman

(Universitas Panca Sakti Bekasi)

Implementasi Metode Prototype Pada Sistem Peminjaman Alat Kerja Berbasis Web

Di PT SK Metalindo

Ali Mulyanto, Arjun Gunawan

(Univeritas Panca Sakti Bekasi)

Aplikasi Tata Cara Wudhu Menggunakan Teknologi Augmented Reality

Sebagai Media Pembelajaran Di TK Al Fatih

Ahmad Yakub , Idarul Fadli

(Universitas Panca Sakti Bekasi ${ }^{12}$ )

Sistem Pakar Diagnosa Penyakit Ayam Petelur Menggunakan Metode Certainty Factor

Berbasis Web Mochammad

Taufiq Hidayat, Ali Mulyanto

(Universitas Panca Sakti Bekasi ${ }^{12}$ ) 
Penerapan Metode Prototyping Dalam Perhitungan Hasil Produksi Menggunakan

Arduino Uno R3 Dan Php Di PT. Indonesia Epson Industry

Amandha Aulia, Ajar Rohmanu

(Universitas Panca Sakti Bekasi ${ }^{12}$ )

System Pendukung Keputusan Penentuan Guru Teladan Dengan Metode Profile Matching

Hasbulloh, Agmawarnida

(Universitas Panca Sakti Bekasi ${ }^{1,2}$ )

Implementasi Waterfall Method Pada Aplikasi Buku Induk Siswa Berbasis Web

Idam Holid, Yogie Krisnayadi

(Universitas Panca Sakti ${ }^{12}$ )

Pengembangan Text To Speech Media Pembelajaran Untuk Pengenalan

Anggota Tubuh Manusia Kelas V Sekolah Dasar

Juwanda Saputra, Ali Mulianto

(Teknik Infomratika Fakulutas Sains dan Teknologi ${ }^{12}$ )

Perancangan Sistem Peminjaman Barang Berupa Aset Tetap Berbasis Web

Pada Lembaga Permasyarakatan Kelas II A Banceuy Bandung

Guntur Salasa Priambodo, Perwito, Candra Mecca Sufyana

(Politeknik Piksi Ganesha Bandung ${ }^{1,2,3}$ )

Metode Pemilihan Karyawan Terbaik Sebagai Penentu Goodwill Perguruan Tinggi

Dengan Menggunakan Metode Topsis (Studi Kasus Perguruan Tinggi Di Lampung Utara)

Dwi Sartika, Pakarti Riswanto

(STMIK Dian Cipta Cendikia Kotabumi)

Sistem Pendukung Keputusan Pemilihan Merek Smartphone Menggunakan

Metode Analytical Hierarchy Process (AHP)

Ade Kiki Fatmawati, Muhammad Sultan Raflie, Norma Yunita

(Universitas Nusa Mandiri ${ }^{123}$ )

Pattern Recognition Aksara Lampung Menggunakan Algoritma Neural Network

Metode Analytical Hierarchy Process (AHP)

Nopiyanto, Rahmadi

(Universitas Panca Sakti Bekasi) 


\title{
PATTERN RECOGNITION AKSARA LAMPUNG MENGGUNAKAN ALGORITMA NEURAL NETWORK
}

\author{
Nopiyanto ${ }^{1}$, Rahmadi $^{2}$ \\ Universitas Panca Sakti Bekasi; \\ Jl. Raya Hankam No. 54, Kota Bekasi, Indonesia \\ Email : nopi@mydrive.id ${ }^{1}$, rahmadi1203@gmail.com ${ }^{2}$
}

\begin{abstract}
ABSTRAK
Indonesia merupakan Negara yang terdiri dari berbagai macam suku dan budaya, Indonesia juga memiliki berbagai macam bahasa daerah, salah satunya merupakan bahasa Lampung. Bahasa Lampung merupakan bahasa asli suku lampung, didalam bahasa lampung terdapat aksara yaitu aksara lampung. Aksara lampung memiliki 20 kepala bahasa dan 12 tanda baca. Pada penelitian ini dilakukan analisa pengenalan tulisan berdasarkan perubahan iterasi dengan menggunakan metode neural network. Neural network merupakan jaringan saraf yang terdiri dari unit dasar yang seperti analog dengan neuron, neural network dibagi berdasarkan 3 layer yaitu input layer, hidden layer dan output layer. Dimana setiap node pada masing-masing layer memiliki suatu error rate, yang akan digunakan untuk proses training. Pada penelitian ini akan menggunakan bahasa pemograman python. Percobaan untuk induk surat akan menggunakan 20 huruf aksara lampung dengan masing-masing huruf terdapat 10 pengujian citra, dan percobaan untuk anak surat akan menggunakan 12 huruf anak aksara lampung dengan masing-masing huruf terdapat 10 pengujian citra, sehingga total keseluruhan dataset mejadi 320 citra. Hasil yang diperoleh dari proses pemeriksaan masing-masing adalah 75\%, untuk induk surat dengan sebaran 135 citra terdeteksi benar dan 45 citra tidak terdeteksi dengan benar. Untuk anak surat 81 citra terdeteksi dengan benar dan 27 citra tidak terdeteksi dengan benar.
\end{abstract}

Kata Kunci : Neural Network, Aksara Lampung, Computer Vision, Python.

\begin{abstract}
Indonesia is a country consisting of various tribes and cultures, Indonesia also has regional languages, one of whichis the lampung language. Lampung language is the original language of the lampung tribe, in the lampung language there is s script, namely the lampung script. The lampung script has 20 language heads and 12 punctuation marks. In this study, an analysis of writing recognition based on iteration changes was carried out using the neural network method. Neural network is a neural network consisting of basic units that are analogous to neurons. Neural network are devided based on 3 layer, namely the input layer, hidden layer, and output layer. Where each node in each layar has an error rate, which will be used for the training process. In this study, the python programming language will be used. The experiment for the main letter will use 20 Lampung script letters with 10 image tests for each latter, and the sub-letter experiment will use 12 lampung script latters with 10 image tests for each letter, so that the total dataset becomes 320 images. The results obtained from each inspection process are $75 \%$ for the main letter with a distribution of 135 images detected correctly and 45 iamges not detected correctly. For letter children, 81 images were detected correctly and 27 images were not detected correctly.
\end{abstract}

Keywords : Neural Network, Lampung Script, Computer Vision, Python.

\section{Pendahuluan}


Dizaman moderen ini, teknologi berkembang sangat pesat. Baik dalam dunia kerja, pendidikan, bahkan didalam kehidupan sehari-hari. Semuanya dimudahkan dengan teknologi yang semakin berkembang. Salah satunya adalah teknologi dalam bidang Artificial Intelligenc (AI), teknologi AI mengakses informasi yang diinginkan secara cepat dan tepat, contohnya adalah mempelajari dasar - dasar penulisan Aksara Lampung.

Aksara Lampung merupakan aksara asli dari Provinsi Lampung sebagai aksara local. Penyusunan aksara Lampung dilakukan kata perkata sehingga menjadi sebuah kalimat. Didalam aksara Lampung terdapat 20 kepala bahasa dan 12 tanda baca. Namun tidak semua orang dapat mengerti ilmu dasar aksara lampung, baik itu anak-anak sekolah dasar, maupun mereka yang sudah dewasa, karena aksara lampung susah di pelajari.

Dengan latar belakang yang telah dimukakan sebelumnya, penulis ingin mengangkat judul dengan tema: "Pattern Recognition Aksara Lampung Menggunakan Algoritma Neural Network".

\section{Landasan Teori}

Teori yang akan dijelaskan yaitu : Artificial Intelligence (AI), Machine Learning, Neural Network, Pattern Recognition, Pengolahan Citra Digital, Python, Tensorflow, Keras.

\subsection{Artificial Intelligence (AI)}

Artificial Intelligence (AI) bagian dari ilmu komputer yang mempelajari bagaimana membuat mesin (komputer) dapat melakukan pekerjaan seperti dan sebaik yang dilakukan oleh manusia, bahkan bisa lebih baik daripada yang dilakukan manusia.

\subsection{Machine Learning}

Machine Learning atau pembelajaran mesin adalah turunan dari ilmu komputer yang berkembang dari studi pengenalan pola dan teori pembelajaran komputasi dalam kecerdasan buatan atau Artificial Intelligence (AI)

\subsection{Neural Network}

Merupakan jaringan saraf yang terdiri dari unit dasar yang seperti analog dengan neuron. Unitunit ini dihubungkan satu sama lain oleh koneksi yang kekuatannya dapat dimodifikasi sebagai hasil dari proses pembelajaran atau algoritma. Masing-masing unit ini mengintegrasikan secara independen (secara paralel) informasi yang diberikan oleh sinapsisnya untuk mengevaluasi keadaan aktivasinya. Algoritma neural network ini mengadopsi dari kemampuan otak manusia yang mampu memberikan stimulasi/rangsangan, melakukan proses dan memberikan output.

\subsection{Konsep Neural Network}

\section{Proses Kerja Jaringan Syaraf Pada Otak Manusia}

Ide dasar Neural Network dimulai dari otak manusia, dimana otak memuat sekitar $10^{11}$ neuron. Neuron ini berfungsi memproses setiap informasi yang masuk. Satu neuron memiliki 1 akson, dan minimal 1 dendrit. Setiap sel syaraf terhubung dengan syaraf lain, jumlahnya mencapai sekitar $10^{4}$ sinapsis. Masing-masing sel itu saling berinteraksi satu sama lain yang menghasilkan kemampuan tertentu pada kerja otak manusia. Dibawah ini gambar dari beberapa bagian otak manusia.

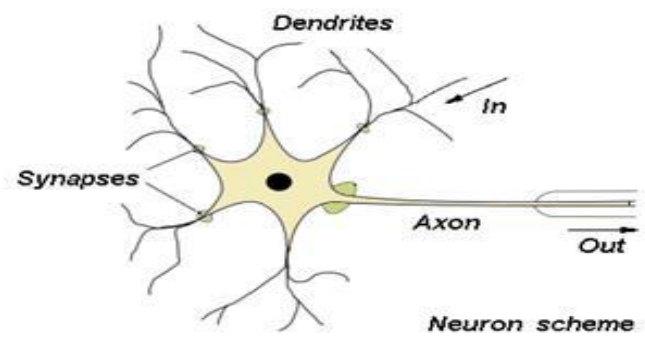

Gambar: Struktur neuron pada otak manusia. 
1. Dendrit (Dendrites) berfungsi untuk mengirimkan impuls yang diterima ke badan sel syaraf.

2. Akson (Axon) berfungsi untuk mengirimkan impuls dari badan sel ke jaringan lain

3. Sinapsis berfungsi sebagai unit fungsional di antara dua sel syaraf.

Proses yang terjadi pada otak manusia adalah:

Sebuah neuron menerima impuls dari neuron lain melalui dendrit dan mengirimkan sinyal yang dihasilkan oleh badan sel melalui akson. Akson dari sel syaraf ini bercabang-cabang dan berhubungan dengan dendrit dari sel syaraf lain dengan cara mengirimkan impuls melalui sinapsis.

\section{Struktur Neural Network}

Dari struktur neuron pada otak manusia, dan proses kerja yang dijelaskan di atas, maka konsep dasar pembangunan neural network buatan (Artificial Neural Network) terbentuk. Ide mendasar dari Artificial Neural Network (ANN) adalah mengadopsi mekanisme berpikir sebuah sistem atau aplikasi yang menyerupai otak manusia, baik untuk pemrosesan berbagai sinyal elemen yang diterima, toleransi terhadap

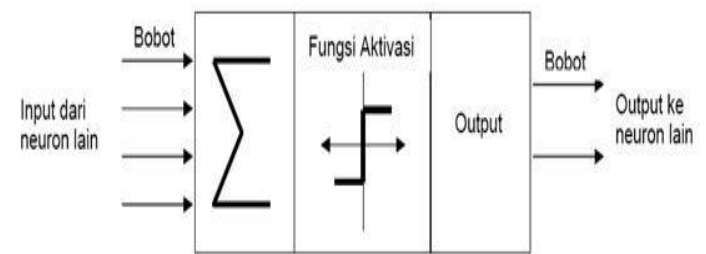

kesalahan/error, dan juga parallel processing.

Gambar: struktur neural network.

Karakteristik dari neural network dilihat dari pola hubungan antar neuron, metode penentuan bobot dari tiap koneksi, dan fungsi aktivasinya. Gambar tersebut menjelaskan struktur neural network secara mendasar, yang dalam kenyataannya tidak hanya sederhana seperti itu.
2. Output, berfungsi seperti akson

3. Fungsi aktivasi, berfungsi seperti sinapsis

Proses pada ANN dimulai dari input yang diterima oleh neuron beserta dengan nilai bobot dari tiap-tiap input yang ada. Setelah masuk ke dalam neuron, nilai input yang ada akan dijumlahkan oleh suatu fungsi perambatan (summing function), yang bisa dilihat seperti pada di gambar dengan lambang sigma $\left(\sum\right)$. Hasil penjumlahan akan diproses oleh fungsi aktivasi setiap neuron, disini akan dibandingkan hasil penjumlahan dengan threshold (nilai ambang) tertentu. Jika nilai melebihi threshold, maka aktivasi neuron akan dibatalkan, sebaliknya, jika masih dibawah nilai threshold, neuron akan diaktifkan.

\subsection{Pattern Recognition}

Pattern Recognition Sebuah kamus inggris mendefinisikan sebuah pola (pattern) sebagai satu contoh atau model sesuatu yang dapat disalin. Sebuah pola adalah juga tiruan sebuah model. Tetapi disaat menjelaskan berbagai tipe objek dalam dunia fisik dan abstrak, definisi yang muncul dalam ingatan - sebuah pola adalah setiap antar hubungan data (analog atau digital), kejadian dan/atau konsep yang dapat dibedakan. Bentuk wajah, sebuah meja, urutan nada sebait musik, tema sebuah sajak atau simponi, jejak yang dibuat partikel pada pelat fotografik, kesemuanya merupakan tipe yang berlainan dari pola-pola. Jadi, pengenalan sebuah wajah, sebait musik, lukisan, perkataan dicetak, kesemuanya adalah masalah pengenalan pola.

\subsection{Pengolahan citra digital}

Pengolahan citra digital (Digital Image Processing) adalah sebuah disiplin ilmu yang mempelajari tentang teknik-teknik mengolah citra. Citra yang dimaksud disini adalah gambar diam (foto) maupun gambar bergerak (yang berasal dari webcam). Sedangkan digital disini mempunyai maksud bahwa pengolahan

1. Input, berfungsi seperti dendrite 
citra/gambar dilakukan secara digital menggunakan komputer.

\section{Citra}

merupakan fungsi kontinyu (continue) dengan intensitas cahaya pada bidang dua dimensi. Agar dapat diolah dengan komputer digital, maka suatu citra harus dipresentasikan secara numerik dengan nilai-nilai diskrit.

\section{Citra Biner}

Citra biner (binary image) adalah citra digital yang hanya memiliki 2 kemungkinan warna, yaitu hitam dan putih. Pembentukan citra biner memerlukan nilai batas keabuan yang akan digunakan menjadi nilai patokan. Piksel dengan 10 derajat keabuan lebih besar dari nilai batas akan diberi nilai 1 dan sebaliknya piksel dengan derajat keabuan lebih kecil dari nilai batas akan diberi nilai 0 . Citra biner sering sekali muncul sebagai hasil dari proses pengolahan, seperti segmentasi, pengambangan, morfologi ataupun dithering. Fungsi dari binerisasi sendiri adalah untuk mempermudah proses pengenalan pola, karena pola akan lebih mudah terdeteksi pada citra yang mengandung lebih sedikit warna.

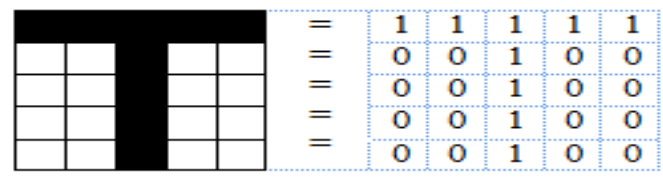

Gambar Citra Biner

\section{8 python}

Python adalah program yang sangat terkenal yang digunakan untuk membuat kode komputer. Dapat digunakan untuk melakukan berbagai aktivitas, mulai dari perhitungan matematika dasar hingga pengkodean situs web dan pemrosesan data.

\subsection{Tensorflow}

Tensorflow adalah salah satu open source library untuk pemrograman berbasis dataflow.
Mempunyai banyak library untuk matematika dan sering digunakan untuk pengaplikasian machine learning seperti neural networks.

\subsection{Keras}

Keras merupakan pembelajaran mendalam yang ditulis dengan python. yang dibuat untuk mempermudah pembelajaran terhadap komputer.

\section{Metode Penelitian}

Dalam penelitian ini dilakukan beberapa tahapan. tahapan yang dilakukan antara lain yaitu pengkondisian dataset, preposesing dataset, proses training dan testing.

Pengkondisian dataset

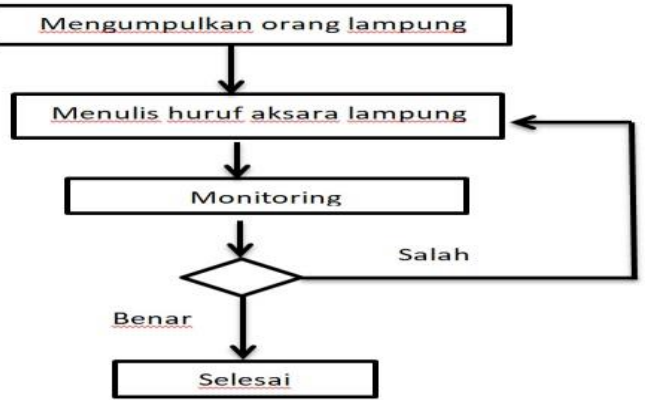

Setelah melakukan riset secara langsung, dataset yang terkumpul berjumlah 20 folder dataset kelabai surat dan 12 folder dataset anak surat. Setiap folder terdapat 10 dataset yang berbeda beda bentuknya, sehingga total keseluruhan terdapat 320 citra.

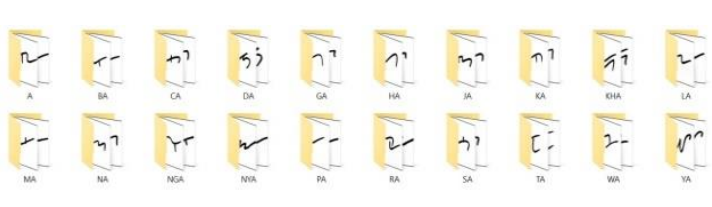

Gambar 1. Dataset kelabai surat

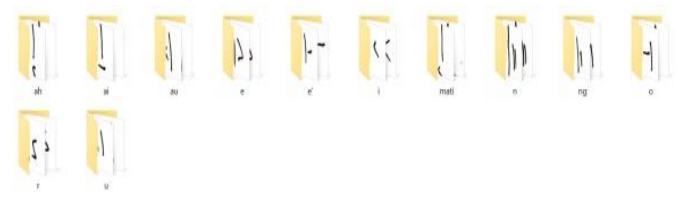

Gambar 2. Dataset anak surat 


\subsection{Proses training dan testing}

Dalam proses training dan testing metode yang digunakan adalah Neural Network atau dikenal dengan JST ( Jaringan Saraf Tiruan ). Dataset yang dikumpulkan dibagi menjadi 2 bagian yaitu data training dan testing. Untuk mendapatkan hasil, maka dilakukan suatu tahapan atau proses training dan testing. Tahap pertama yang dilakukan adalah mentraining data yang sudah dibagi, setelah dilakukan training maka selanjutnya menghitung nilai loss dan akurasi dari hasil testing. Sedangkan data testing dapat dari hasil akurasi data yang sudah di training. Untuk menentukan epoch, dilakukan testing satu kali agar mendapatkan eror dan mendapatkan hasil yang baik. Kemudian setelah tahap itu selesai, selanjutnya melakukan tahapan pelebelan dan pemisahan data training dan testing, dilanjutkan dengan melatih dataset menggunakan algoritma Neural Network atau JST ( Jaringan Saraf Tiruan ).

\section{Hasil dan Pembahasan}

Pada tahapan ini akan membahas tentang hasil dan pembahasan mengenai pola tulisan aksara lampung dengan menggunakan metode neural network atau JST ( Jaringan Saraf Tiruan ). Sebagai tahapan awal dilakukan training bertujuan untuk memberikan pengetahuan yang nantinya akan digunakan sebagai testing data. Maka akan mendapatkan nilai keakurasian yang didapatkan dari nilai output.

Pada perancangan sistem tahapan yang dilakukan adalah pengumpulan dataset aksara lampung yang diperoleh dari 10 orang warga lampung yang akan digunakan sebagai data training dan testing. Dari hasil melakukan survei secara langsung yaitu dengan mengumpulkan warga asli lampung untuk menulis aksara lampung maka dapat diperoleh data sebanyak 200 data untuk induk surat dan 120 data untuk anak surat. Setelah dataset berhasil dikumpulkan, selanjutnya dilakukan proses reprocessing. Data yang digunakan sebagai dataset harus diubah dengan ukuran yang sama agar lebih mudah pada saat diproses. Ukuran dari gambar yang telah diubah menjadi 478 × 360 pixel seperti pada gambar 3 berikut :

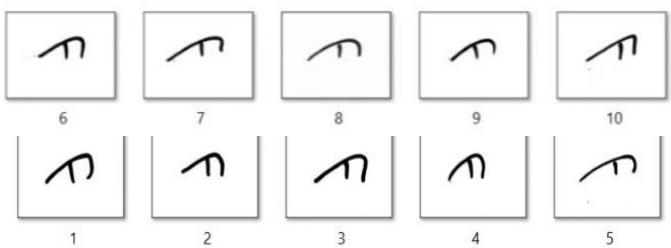

Gambar 3. Citra aksara lampung pada huruf KA

Setelah mengubah size pada image, selanjutnya melakukan label sesuai dengan huruf aksara lampung menjadi 32 folder termasuk kelabai dan anak surat. Setelah melakukan beberapa tahapan, selanjutnya akan dilakukan proses pengujian keakurasian data. Penulis akan melakukan percobaan dengan 10 sample dalam data uji dengan metode Neural Network atau JST ( Jaringan Saraf Tiruan ) dengan 5 iterasi (epoch) Hasil pencocokan data yang telah dilakukan seperti table berikut :

\begin{tabular}{|c|c|c|c|c|}
\hline No & Label & $\begin{array}{c}\text { Jumlah } \\
\text { dataset }\end{array}$ & $\begin{array}{c}\text { Data } \\
\text { terdeteksi }\end{array}$ & $\begin{array}{c}\text { Data } \\
\text { tidak } \\
\text { terdeteksi }\end{array}$ \\
\hline 1 & $\mathrm{AN}$ & 10 & 9 & 1 \\
\hline 2 & $\mathrm{I}$ & 10 & 8 & 2 \\
\hline 3 & $\mathrm{E}$ & 10 & 7 & 3 \\
\hline 4 & $\mathrm{E}^{\prime}$ & 10 & 5 & 5 \\
\hline 5 & $\mathrm{NG}$ & 10 & 7 & 3 \\
\hline 6 & $\mathrm{R}$ & 10 & 5 & 5 \\
\hline 7 & $\mathrm{AU}$ & 10 & 6 & 4 \\
\hline 8 & $\mathrm{U}$ & 10 & 8 & 2 \\
\hline 9 & $\mathrm{O}$ & 10 & 7 & 3 \\
\hline 10 & $\mathrm{Al}$ & 10 & 6 & 4 \\
\hline 11 & $\mathrm{AH}$ & 10 & 7 & 3 \\
\hline 12 & MATI & 10 & 8 & 2 \\
\hline
\end{tabular}

Tabel 1. Table Induk Sura

\begin{tabular}{|c|c|c|c|c|}
\hline No & Label & $\begin{array}{l}\text { Jumbah } \\
\text { dataset }\end{array}$ & $\begin{array}{l}\text { Data } \\
\text { terdeteksi }\end{array}$ & $\begin{array}{l}\text { Data tidak } \\
\text { terdeteksi }\end{array}$ \\
\hline 1 & KA & 10 & 9 & 1 \\
\hline 2 & GA & 10 & 7 & 3 \\
\hline 3 & NGA & 10 & 6 & 4 \\
\hline 4 & PA & 10 & 8 & 2 \\
\hline 5 & BA & 10 & 7 & 3 \\
\hline 6 & MA & 10 & 6 & 4 \\
\hline 7 & TA & 10 & 9 & 1 \\
\hline 8 & DA & 10 & 6 & 4 \\
\hline 9 & NA & 10 & 9 & 1 \\
\hline 10 & CA & 10 & 7 & 3 \\
\hline 11 & JA & 10 & 8 & 2 \\
\hline 12 & NYA & 10 & 6 & 4 \\
\hline 13 & YA & 10 & 8 & 2 \\
\hline 14 & A & 10 & 8 & 2 \\
\hline 15 & LA & 10 & 10 & 0 \\
\hline 16 & RA & 10 & 5 & 5 \\
\hline 17 & SA & 10 & 7 & 3 \\
\hline 18 & WA & 10 & 9 & 1 \\
\hline 19 & HA & 10 & 8 & 2 \\
\hline 20 & KHA & 10 & 5 & 5 \\
\hline
\end{tabular}

Table 2. Tabel Anak Surat 
Setelah melalui beberapa tahapan, selanjutnya akan dilakukan proses pengujian untuk mengetahui keakurasian data serta lossnya. Hasil dari pengujian $100 \%$ data diperoleh output sebesar $25 \%$ data loss, maka dapat disimpulkan tingkat keakurasian data sebesar $75 \%$.

\section{Kesimpulan}

Setelah dilakukan berapa tahapan dan proses didapatkan nilai akurasi data sebesar $75 \%$, untuk mendapatkan hasil klasifikasi melalui metose neural network atuau JST ( Jaringan Saraf Tiruan ) kita tidak perlu memiliki data yang besar, selain itu keuntungan memiliki jumlah sample yang sedikit dapat mempercepat dalam pemrosesan data. Lain daripada itu, masih terdapat banyak hal yang harus dilakukan perbaikan, mengingat model ini belum diuji menggunakan dataset lain atau dengan menggunakan metode lain.

\section{DAFTAR PUSTAKA}

[1] Ananda Riska Mita Izati, H. B. (2019). Penerapan Metode Artificial Neural Network Dalam Peramalan Jumlah Kunjungan Ibu Hamil (K4). Jurnal Beometrika Dan Kependudukan, 11-20.

[2] Aulia Yudha Prathama, A. A. (2017). Pendekatan Ann (Artificial Neural Network) Untuk Penentuan Prosentase Bobot Pekerjaan Dan Estimasi Nilai Pekerjaan Struktur Pada Rumah Sakit Pratama. Jurnal Teknosains, 1-82.

[3] Chamsudin, A. (N.D.). Implementasi Neural Network Untuk Memprediksi Jumlah Penderita Tuberculosis. Emitor: Jurnal Teknik Elektro.

[4] Eka Dina Juliani Utari Ms, I. G. (2019). Pengenalan Pola Tulisan Tangan Huruf Sasak Menggunakan Metode Integral Projection Dan Neural Network. J-Cosine, Vol. 3, No. 1, Juni 2019.
[5] Haumahu, J. P. (2019). Implementasi Jaringan Syaraf Tiruan Untuk Pengenalan Pola Notasi. Jurnal Riset Komputer (JURIKOM), Vol. 6 No. 3, Juni 2019, 255-259.

[6] Herman, L. S. (2018). Pengenalan Angka Tulisan Tangan Menggunakan Jaringan Syaraf Tiruan. Ilkom Jurnal Ilmiah Volume 10 Nomor 2 Agustus 2018.

[7] Kurniawansyah, A. S. (2018). Implementasi Metode Artificial Neural Network Dalam Memprediksi Hasil Ujian Kompetensi Kebidanan (Studi Kasus: Akademi Kebidanan Dehasen Bengkulu). Jurnal Pseudocode, Volume V Nomor 1, Februari 2018.

[8] Trisna Yuniarti, I. R. (N.D.). Penggunaan Artificial Neural Network (Ann) Untuk Memodelkan Volume Ekspor Crude Palm Oil (Cpo) Di Indonesia. Ready Star - 2.

[9] Yuan Octavia D.P., A. A. (N.D.). Studi Prakiraan Beban Listrik Menggunakan Metode Artificial Neural Network. Jurnal Teknologi Elektro Dan Kejuruan. 